\title{
Sports-related brain injuries: connecting pathology to diagnosis
}

\author{
*James Pan, BS, ${ }^{1}$ lan D. Connolly, MS, ${ }^{1}$ Sean Dangelmajer, BA, ${ }^{2}$ James Kintzing, BS, ${ }^{3}$ \\ Allen L. Ho, MD, ${ }^{1}$ and Gerald Grant, MD ${ }^{1}$ \\ Departments of ${ }^{1}$ Neurosurgery, ${ }^{2}$ Orthopaedic Surgery, and ${ }^{3}$ Bioengineering, Stanford University School of Medicine, Stanford, \\ California
}

\begin{abstract}
Brain injuries are becoming increasingly common in athletes and represent an important diagnostic challenge. Early detection and management of brain injuries in sports are of utmost importance in preventing chronic neurological and psychiatric decline. These types of injuries incurred during sports are referred to as mild traumatic brain injuries, which represent a heterogeneous spectrum of disease. The most dramatic manifestation of chronic mild traumatic brain injuries is termed chronic traumatic encephalopathy, which is associated with profound neuropsychiatric deficits. Because chronic traumatic encephalopathy can only be diagnosed by postmortem examination, new diagnostic methodologies are needed for early detection and amelioration of disease burden. This review examines the pathology driving changes in athletes participating in high-impact sports and how this understanding can lead to innovations in neuroimaging and biomarker discovery.
\end{abstract}

http://thejns.org/doi/abs/10.3171/2016.1.FOCUS15607

KEY WORDS traumatic brain injury; neurodegeneration; biomarkers; imaging; concussion; chronic traumatic encephalopathy; sports

$\mathrm{M}$ ANY sports-related brain injuries involve mild traumatic brain injuries (mTBIs), which result from physical blows to the head sustained over a period of time. Sports associated with an increased risk of head injury include American football, ice hockey, soccer, rugby, the martial arts, boxing, and bicycling..$^{21,90}$ These injuries are often unrecognized, undiagnosed, or underreported, which reflects the fact that this is a growing medical concern, often labeled a "silent epidemic." 8,66 Chronic exposure to mild brain injuries can result in long-term neurological consequences and represents a spectrum of disorders. The most remarkable outcome of mTBI is termed chronic traumatic encephalopathy (CTE), a clinical syndrome that is associated with neurodegeneration and behavioral, cognitive, and/or motor deficits. Although this disease has distinct pathological features, CTE is considered a diagnosis of exclusion because only postmortem biopsies can confirm the diagnosis. Therefore, new diagnostic methods need to be developed to: 1) inform patients of a definitive diagnosis, 2) better understand the epidemiology and risk factors of the disease, and 3) implement intervention programs to prevent any potential long-term complications. This review examines how understanding the pathology and molecular changes associated with repeated head trauma can lead to the discovery of novel imaging techniques and biomarkers.

\section{Mild Traumatic Brain Injury and CTE}

Chronic traumatic encephalopathy has evolved from the so-called punch-drunk syndrome, which was used to describe a distinct neuropsychiatric condition that seemed to affect boxers, eventually becoming known as dementia pugilistica during the 1920s and 1930s. Symptoms such

ABBREVIATIONS AD = Alzheimer's disease; $A P O E=$ apolipoprotein E; $A S L=$ arterial spin labeling; $B B B=$ blood-brain barrier; $B O L D=$ blood oxygen level-dependent; CA = cornu ammonis; CTE = chronic traumatic encephalopathy; DTI = diffusion tensor imaging; FA = fractional anisotropy; fMRI = functional MRI; GFAP = glial fibrillary acidic protein; GRE = gradient recall echo; miRNA = microRNA; MRS = MR spectroscopy; $\mathrm{mTBI}=$ mild traumatic brain injury; NFL = National Football League; NFT = neurofibrillary tangle; NINDS = National Institute of Neurological Disorders and Stroke; NSE = neuron-specific enolase; p-tau = phosphorylated tau; SWI = susceptibility-weighted imaging; TDP-43 = TAR DNA-binding protein 43; ${ }^{18} \mathrm{~F}-\mathrm{FDDNP}=2-(1-\{6-[(2-[$ fluorine-18]fluoroethyl)(methyl)amino]-2-naphthyl\}-ethylidene)malononitrile.

SUBMITTED December 1, 2015. ACCEPTED January 19, 2016.

INCLUDE WHEN CITING DOI: 10.3171/2016.1.FOCUS15607.

* Mr. Connolly, Mr. Dangelmajer, and Mr. Kintzing contributed equally to this work. 
as unsteady gait, mental confusion, slowed muscular response, hesitant speech, tremors, and parkinsonism were common. ${ }^{91}$ Case reports and series started to appear several decades later, during the 1950s and 1960s, describing pathological features associated with this condition such as cerebral atrophy, neuronal loss, gliosis, and argyrophilic neurofibrillary tangles. ${ }^{18,27,81,102,123}$

Over time, investigators began to realize that the neurocognitive deficits seen in dementia pugilistica also affected men and women subjected to a broad range of brain trauma including physical abuse, head banging, poorly controlled epilepsy, and rugby. As discussed by McKee et al., ${ }^{86}$ the term "chronic traumatic encephalopathy" was first introduced by Critchley in 1949 to more generally describe this condition as a collection of clinical symptoms. ${ }^{86}$ This term was further refined by Corsellis et al. in 1973, who proposed 4 initial major criteria that established a neuropathological identification of CTE. ${ }^{26,131} \mathrm{Up}$ to the turn of the 21 st century, many studies were published noting similar symptoms among boxers, although no prospective longitudinal studies were performed to track progression of their symptoms. ${ }^{91}$

Interest in CTE spiked during the early 21st century when Omalu and colleagues ascribed this condition to an American football player ${ }^{108}$ and a professional wrestler. ${ }^{109}$ Subsequently, this disease has also been identified in soccer, baseball, ice hockey, and rugby players, in addition to military personnel. Tauopathies with overlapping CTE features have also been described in individuals exposed to a single moderate or severe TBI. ${ }^{64,130}$ Until very recently, CTE was a poorly defined term that was used inconsistently among investigators. It was not until 2015 that the National Institute of Neurological Disorders and Stroke (NINDS) convened a panel to arrive at a consensus neuropathological definition of CTE. 86

To date, CTE has only been found in individuals with a history of repetitive head trauma. ${ }^{42,87}$ Although the temporal sequence of events between initial head trauma and the development of neurodegeneration is unclear, it has been acknowledged that there is an association between mTBIs and CTE, with repetitive head trauma appearing to be a necessary event for the development of CTE. ${ }^{132}$ The link between mTBIs and tauopathy was classically demonstrated by Corsellis and Brierley, who also noted that mild, repetitive, traumatic insults to the head had a distinct histopathological picture from that of severe single-incident TBIs. ${ }^{25}$ The association between mTBIs and CTE was further demonstrated by an assessment of 224 randomly selected professional boxers, which showed that $17 \%$ of them displayed a "relatively stereotyped" clinical picture of CTE that included various neuropsychiatric deficits. ${ }^{122}$ The risk of developing these deficits was also positively correlated with duration of participation in the sport, older age at retirement, and length of a boxer's career. Similarly, in a population of American football players with autopsy-confirmed CTE, the severity of disease was positively correlated to duration of exposure to the sport, years since retirement, and age at death..$^{90}$ Bieniek et al., using the most recent NINDS criteria for CTE, reviewed clinical records and brains of 1721 contact sport athletes in the Mayo Clinic Brain Bank and found evidence of CTE in $32 \%$ of contact sport athletes. ${ }^{13}$ Although all confirmed cases of CTE have a history of exposure to repetitive mild brain trauma, not all individuals exposed to such trauma will develop CTE.

Despite the lack of research demonstrating a concrete cause-effect relationship in humans, there has been promising work in animal studies as various transgenic mouse models have been used to study the neurodegenerative effects of repetitive brain injury. Hoshino and colleagues applied repetitive mTBI to transgenic mice that expressed a human tau isoform. ${ }^{58}$ After 6 months, the authors observed increased loss of cortical neurons as well as phosphorylated tau. In another study, which used mice that expressed all 6 isoforms of wild-type human tau protein, increased phosphorylation of tau was found in mice that were exposed to repetitive mTBI but not to a single mTBI. ${ }^{106}$ Another mouse model of brain trauma was able to recapitulate several features of CTE following blast injury, similar to those suffered by US military veterans. ${ }^{46}$ Two weeks after blast exposure, mice demonstrated phosphorylated tauopathy, myelinated axonopathy, chronic inflammation, and neurodegeneration in the absence of macroscopic tissue damage or hemorrhage. These animal studies further strengthen the causal relationship between mTBI and chronic neurodegeneration and can provide a more thorough temporal sequence of events to explain the mechanisms driving these pathologies.

Although a large number of investigators label CTE as a progressive disease, it is important to note the lack of prospective cohort studies to fully support this assertion. ${ }^{31}$ However, studies do suggest that mTBIs are a major risk factor for the development of CTE; therefore, a major research goal must be to integrate relevant diagnostic modalities along the entire brain injury spectrum. This will allow clinicians to use specific imaging findings and biomarker assays to identify early stages of the disease and to track specific parameters over time.

\section{Pathology of CTE}

Modern case reports and case series have described various gross pathological features associated with CTE such as diffuse brain atrophy, ventricular enlargement, cerebellar gliosis, and degeneration of the substantia nigra pars compacta and cavum septum pellucidum with or without septal fenestration. ${ }^{26,87-90,107}$ More severe cases of the disease are associated with atrophy of the medial temporal lobe, thalamus, hypothalamus, and mammillary bodies. ${ }^{66}$

Histological changes include hyperphosphorylated tau protein-associated neurofibrillary tangles (NFTs), neuropil neurites, and astrocytic tangles. ${ }^{9,87,107}$ The most recent National Institutes of Health consensus definition of CTE considers perivascular tau accumulation in the depths of cortical sulci to be pathognomonic for a diagnosis of CTE (Fig. 1). ${ }^{86,100}$ This consensus group also describes features of phosphorylated tau (p-tau)-related pathologies that are specific to CTE and can aid in distinguishing it from other neurodegenerative disorders such as Alzheimer's disease (AD). P-tau and NFT accumulation preferentially affect cortical layers II-III in CTE as opposed to layers III and $\mathrm{V}$, which are more commonly seen in AD. Hippocampal 
a

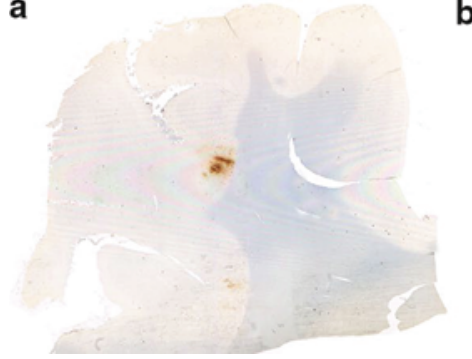

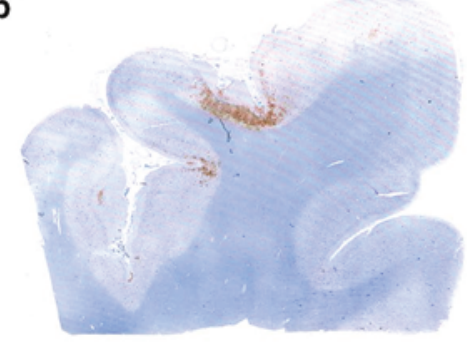

C

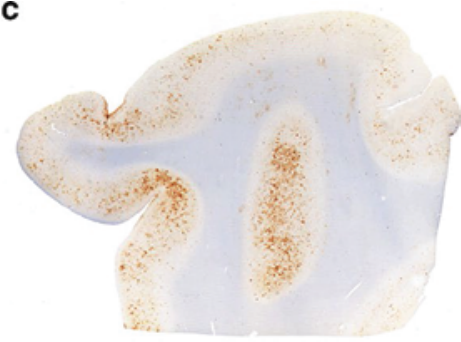

FIG. 1. Immunohistochemical staining for $p$-tau in the brains of 3 autopsy-confirmed CTE cases (a-c) shows characteristic patterns in the depths of cortical sulci, often in an irregular pattern. Modified from McKee et al: Acta Neuropathol 131:75-86, 2016. Creative Commons Attribution (CC BY) license, https://creativecommons.org/licenses/by/4.0/.

involvement includes pretangles, NFTs, and extracellular tangles primarily affecting cornu ammonis (CA) 2 and prominent proximal dendritic swellings in CA4. In AD, these features are primarily observed in CA1 and the subiculum. In CTE, abnormal p-tau aggregates are seen in neurons and astrocytes in the subcortical nuclei, including the mammillary bodies, hypothalamic nuclei, amygdala, nucleus accumbens, thalamus, midbrain tegmentum, and isodendritic core (comprising the nucleus basalis of Meynert, raphe nuclei, substantia nigra, and locus caeruleus). P-tau-positive thorny astrocytes at the glial limitans can be seen at the subpial and periventricular regions. Large grain-like and dot-like structures, which are immunoreactive for $\mathrm{p}$-tau, can also be seen. Other features not related to p-tau that support a diagnosis of CTE include accumulation of TAR DNA-binding protein 43 (TDP-43) in neurons, glial cells, neurites, and inside cellular nuclei. ${ }^{88}$ Other groups have also reported "skip phenomenon," in which histopathological features can be randomly distributed within the same lobe in an irregular fashion. ${ }^{107}$

Beta $(\beta)$-amyloid deposition remains a controversial characteristic of CTE because it occurs inconsistently and is not as strongly associated with CTE as other pathological findings ${ }^{88,91,109,110}$ In 1 study of 68 patients with CTE diagnosed by history and presence of NFTs, $50 \%$ of cases showed signs of diffuse $\beta$-amyloid plaques, and $30 \%$ of cases had classic neuritic plaques seen in AD.$^{90}$ However, $\beta$-amyloid plaques in this cohort were associated with increasing age, which may be attributed to comorbid $\mathrm{AD}$ or other neurodegenerative conditions.

McKee et al. and Omalu et al. have each described a classification system for CTE pathology. Concerning the severity of CTE, McKee et al. developed a staging system for CTE as a function of brain weight and spatial diffuseness of NFTs/p-tau pathologies. This staging system defines CTE starting as mild (Stages I-II) focal lesions at the perivascular sulci of the frontal cortex, progressing to more severe (Stages III-IV) involvement of the medial cortex, medial temporal lobe, diencephalon, and deep brain structures such as the basal ganglia, and eventually involving the brainstem and spinal cord. ${ }^{90}$ In contrast, Omalu et al.'s scheme assigns specific, discrete subtypes to CTE. This phenotype system bins the disease solely based on the spatial location of the lesions. ${ }^{107}$ Furthermore, McKee et al. postulate that CTE requires repetitive mTBI, whereas Omalu et al. state that CTE can be caused by single episodic or repetitive head trauma. The patho- logical classifications of McKee et al. and Omalu et al. are summarized in Tables 1 and 2, respectively.

The exact pathophysiology of CTE is still unclear, although there have been several proposed mechanisms. Direct linear and rotational acceleration of the head can result in diffuse axonal injury to cortical and subcortical areas. These forces exerted on axons result in increased membrane permeability and a perturbation in membrane potential, leading to calcium influx and activation of downstream caspases and calpains. This signaling cascade has been proposed as a trigger point for apoptosis and tau phosphorylation and aggregation. ${ }^{42,44}$

Chronic inflammation and immune excitotoxicity have been proposed as a mechanism by Blaylock and Maroon. ${ }^{14}$ This theory postulates that an initial head injury primes microglia for subsequent injury. Microglia, although activated to a proinflammatory state after an initial brain injury, eventually switch to a reparatory state. However, additional head injuries may cause the microglia to persist in a proinflammatory state, triggering them to release cytokines, chemokines, and inflammatory neuromodulators such as glutamate, aspartate, and quinolinic acid. This series of events is hypothesized to then trigger deposition of hyperphosphorylated tau protein, resulting in neurodegeneration.

The parallels between CTE and other neurodegenerative diseases such as AD may involve mechanisms common to the broader class of diseases known as tauopathies. Cis-p-tau was found to be extremely toxic to the brain and may be the initiating event that leads to CTE in some populations and to $\mathrm{AD}$ in others. ${ }^{97-99} \mathrm{~A}$ recent study by Min et al. has shown that acetylation of tau at Lys174 in a mouse model plays a critical role in the pathophysiology of various tauopathies, including the neurodegenerative process seen in CTE. ${ }^{22}$ Furthermore, it was shown that acetyltransferase inhibitors, salsalate, and salicylate increased tau turnover and reduced tau levels, which suggests that the tau acetylation pathway can be a potential target for treatment.

\section{Diagnostic Approaches and Considerations}

Although the diagnosis and acute management of concussion is well described, ${ }^{45,84,85}$ there are considerable gaps in adequately following up on long-term sequelae that can have important neurological and functional consequences. There is evidence that repeated injury results in cumula- 

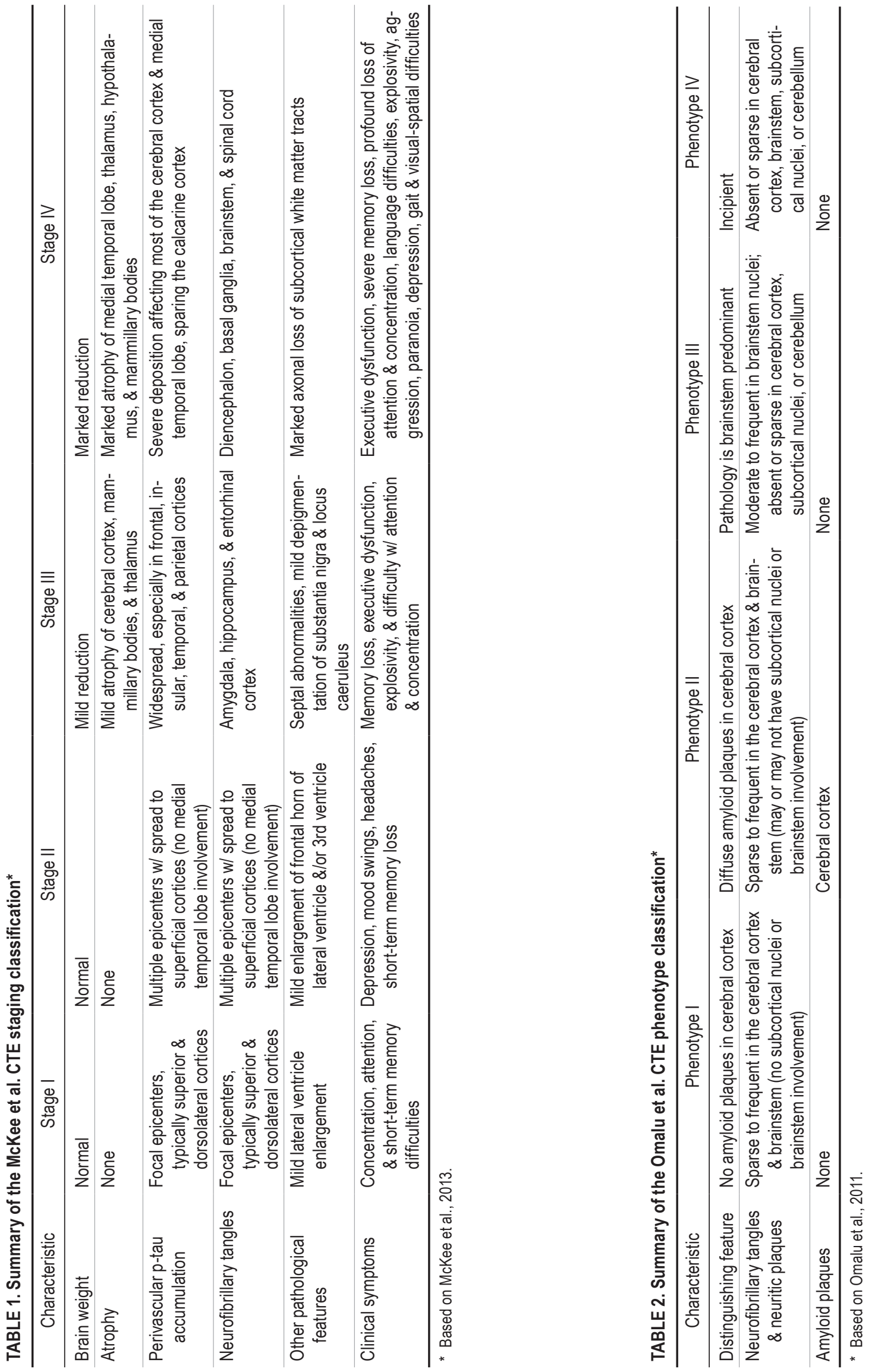
tive neuropsychological damage, with deficits increasing in severity and duration after each separate incident. ${ }^{28,48,83}$ Specific deficiencies include cognitive, behavioral, and motor symptoms.${ }^{90}$ Cognitive symptoms include impaired attention and concentration, memory problems, dementia, executive dysfunction, visuospatial impairment, and language difficulties. Behavioral symptoms such as aggression/agitation, apathy, impulsivity, depression, delusions, and suicidality have also been reported. ${ }^{5}$ Motor symptoms reflect damage to the cerebellar pyramidal systems and manifest as dysarthria, spasticity, parkinsonism, ataxia, and gait disturbances. Although there have been 3 proposed research or clinical sets of diagnostic criteria for CTE, all operate under the assumption that CTE is a diagnosis of exclusion (i.e., all other medical or psychiatric diagnoses must be ruled out). ${ }^{66,94,140}$

A systematic review by Giza et al. attempted to classify categories of athletes who are particularly at risk for developing long-term complications from concussion, which can further aid in selecting patients for diagnostic screening. ${ }^{45}$ Patients with more prominent subjective complaints during and after the acute phase of a concussion (particularly those associated with headache, fatigue, amnesia, dizziness, and disorientation) were found to have an increased risk of developing persistent neurocognitive deficits and of having a longer recovery from the initial concussion. Another risk factor is a history of prior concussions and headaches, both of which have been associated with more severe postconcussion deficits and longer recovery times. Finally, apolipoprotein $\mathrm{E}(A P O E) \varepsilon 4$ genotyping and preexisting learning disabilities can also be associated with an increased risk of developing long-term complications of concussion. However, the consensus is mixed, with studies showing that athletes with the APOE $\varepsilon 4$ genotype were more likely to have cognitive impairment ${ }^{72}$ and other studies suggesting that this allele is not a contributing factor. ${ }^{22,52}$

An ongoing challenge in diagnosis of mTBI and CTE is the presence of comorbid neurodegenerative disease. For example, in a study of 12 former athletes who were confirmed postmortem to have had CTE, 3 also had motor neuron disease. ${ }^{88}$ In another series of 68 patients with confirmed diagnosis of CTE, $8(12 \%)$ also had motor neuron disease, 7 (11\%) had AD, 11 (16\%) had Lewy body disease, and $4(6 \%)$ had frontotemporal dementia..$^{90}$ According to the most recent NINDS consensus, the presence of histopathological features consistent with another neurodegenerative disease excludes CTE as the sole diagnosis. ${ }^{86}$ For example, CA1 predominant neurofibrillary tangles in the hippocampus with amyloid deposition is consistent with AD. Prominent destruction of the cerebellar dentate nucleus with coiled bodies in oligodendrocytes, and tufted astrocytes, are seen in progressive supranuclear palsy. Severe astrocyte tangles in the striatum, pallidum, and cortical and subcortical structures are associated with corticobasal degeneration and globular astrocytic inclusions with globular glial atrophy. Therefore, there is a critical need for highly specific radiological and biological markers of various neurodegenerative disorders. The current lack of such markers reflects a huge knowledge gap in our understanding of this nebulous group of diseases.

\section{Imaging Methodologies}

Recent advances have implicated various radiological methods in evaluating the presence of structural and pathological changes in the setting of CTE and mTBIs; in conjunction with the clinical manifestations of CTE, these methods may aid in establishing a more holistic diagnostic criterion..$^{9,36}$ However, it is important to note that brain injury represents a heterogeneous spectrum of disease, and no single imaging modality can adequately characterize the entire pathological picture. Although gross pathological changes seen in autopsy (e.g., cortical atrophy, degeneration of brain structures, ventricular enlargement, and so on) have been of particular interest from a neuroradiology standpoint, advances in imaging techniques have allowed the detection of ultrastructural, histopathological, and metabolic changes as well. Table 3 provides a summary of various neuroimaging techniques that have been investigated in the context of sports-related brain injuries.

\section{Magnetic Resonance Imaging}

Magnetic resonance imaging allows for the detection of gross cerebral atrophy, ${ }^{77,137,152}$ small contusions, white matter shearing, foci of axonal injury, and small subacute

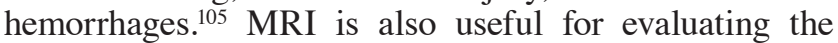
brain-CSF border, distinguishing the interface between gray and white matter, and detecting cerebral edema, which are all important factors to consider when evaluating mTBI. ${ }^{65}$ Such an approach is evident in a study involving 20 young to middle-aged patients who reported 2 or more sports-related mTBIs that occurred at least 6 months prior to enrollment. MRI revealed that a higher number of mTBIs were associated with lower cortical thickness in the bilateral insula, right middle temporal gyrus, and right entorhinal area relative to matched controls. ${ }^{76}$ Similarly, MRI has revealed decreased hippocampal volumes, as well as other nonspecific abnormalities in patients with a history of mTBIs. ${ }^{59,133}$ A study of 20 patients with TBI, who were 16-65 years old, had nonpenetrating TBI that required hospitalization, and/or were victims of high-speed motor vehicle collisions, revealed significant reductions in whole brain volume, white matter volume, and gray matter volume between acute and follow-up scans (range 6-11 months). ${ }^{33}$ These findings coincide with those of a number of studies that exhibited gross reductions in brain volume in various anatomical regions of the brain. ${ }^{38,73,142}$ In a recent study, Strain et al. correlated MRI FLAIR sequence, diffusion tensor imaging (DTI), and arterial spin labeling (ASL) findings with concussion history in a series of 28 retired National Football League (NFL) athletes, 8 of whom had mild cognitive impairment. The results of this study revealed that prior concussion resulting in loss of consciousness is a risk factor for development of mild cognitive impairment (defined as cognitive impairments beyond those expected for the age and education level of that individual) due to hippocampal atrophy, changes in cerebral blood flow, and white matter abnormalities. ${ }^{133}$

In addition to traditional T1- and T2-weighted MRI, other sequences can add to the information obtained from a scan. Susceptibility-weighted imaging (SWI) is a type of gradient recall echo (GRE) sequence, which can be per- 


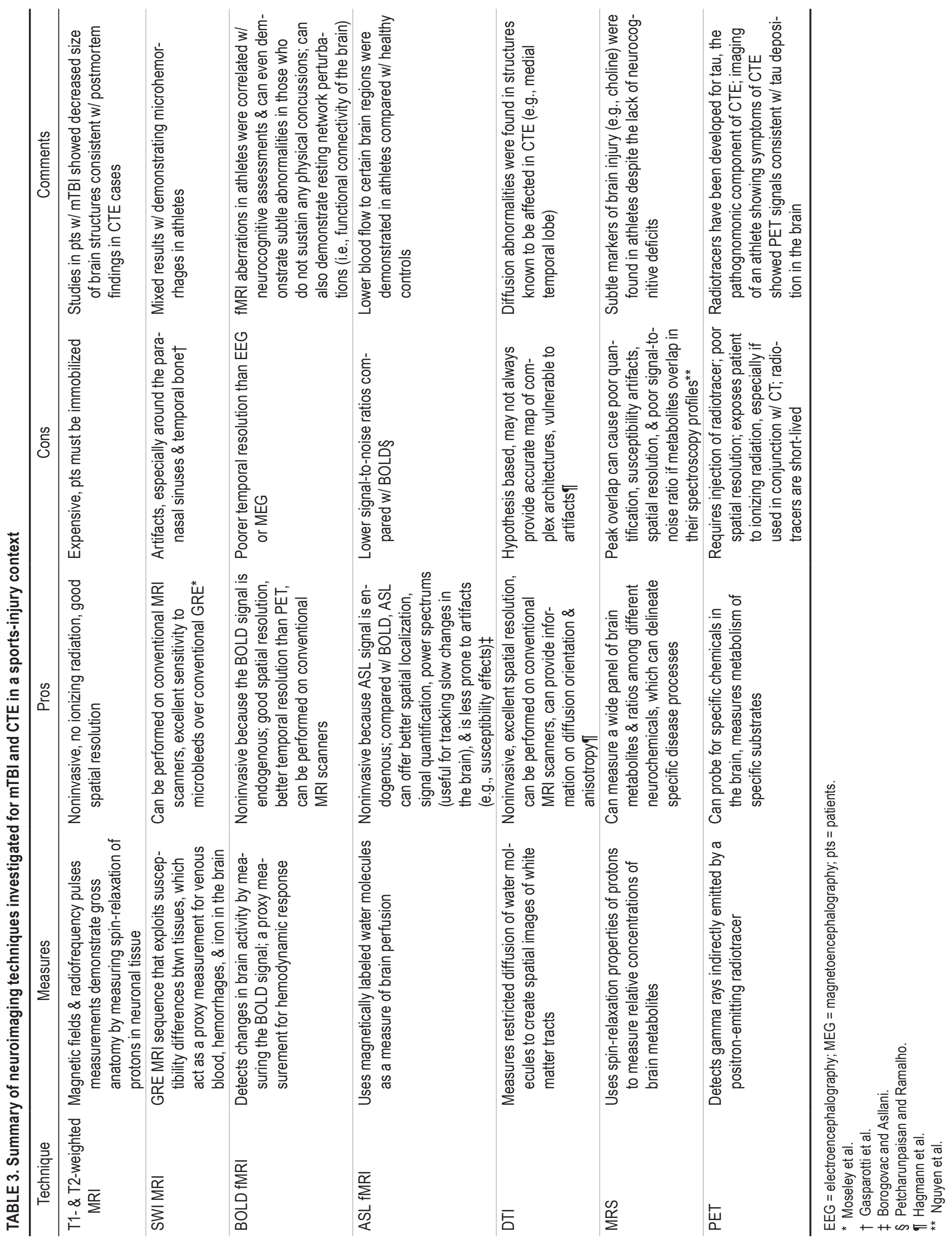


formed on conventional scanners. SWI takes advantage of the magnetic susceptibility differences between tissues and uses them to detect the paramagnetic properties of deoxyhemoglobin. Therefore, this method can detect the presence of venous blood, hemorrhages, and iron in the brain. SWI was successfully used in a cohort of 40 children and adolescents to discern microhemorrhages and diffuse axonal injury after TBI resulting from motor vehicle accidents and sports injuries. ${ }^{136}$ In this study, SWI was more sensitive than T2-weighted GRE sequences, could more accurately and objectively assess early brain injury, and was better correlated with prognostic information and long-term outcomes. In applying this method to a series of 45 male and female collegiate hockey players, Helmer et al. showed that male players with a concussion had a statistically significant increase in hypointensity burden, which correlates to subtle signs of chronic and acute damage to the brain. ${ }^{55}$ However, in another study of 45 retired NFL players, SWI revealed microbleeds in only 4 players, and none of the players in the entire cohort had symptoms suggestive of CTE (specifically dementia, dysarthria, parkinsonism, or cerebellar dysfunction). ${ }^{20}$ These results could potentially put the sensitivity of SWI into question, and longer followup of this cohort is required to correlate early imaging and pathological findings with long-term outcomes.

\section{Functional MRI}

The use of functional MRI (fMRI) has demonstrated utility in detecting abnormal white matter blood oxygen level-dependent (BOLD) signals, with evidence suggesting that BOLD signals can be used to accurately differentiate patients with chronic mTBI from healthy controls. ${ }^{4}$ In a pediatric series of 21 male high school football players with no prior history of concussion, ${ }^{134}$ fMRI revealed alterations in the pattern and amplitude of BOLD signal differences when performing the 2-back and 1-back memory tasks, particularly in the middle and superior temporal gyri in 4 athletes who sustained a concussion during the football season. Interestingly, in 4 other players who did not sustain a concussion, fMRI revealed significantly decreased activation levels in the dorsolateral prefrontal cortex and cerebellum, regions of the brain which are associated with working memory. These changes noted by fMRI were also highly correlated with the ImPACT neurocognitive assessment tool. Another study examined the connectivity of the default mode network of 29 collegiate student athletes, 14 of whom had suffered a previous concussion. ${ }^{63}$ Although each athlete was asymptomatic, fMRI and voxel-based correlation analysis revealed a significant decreased connectivity of the default mode network, which consists of the precuneus/posterior cingulate cortex; medial prefrontal cortex; and medial, lateral, and inferior parietal cortex. The magnitude of connectivity aberrations was also correlated with the number of concussions. These results were also consistent with a similar series of 27 patients with mTBI from the general population. ${ }^{82}$

Arterial spin labeling is another fMRI method, which uses magnetically labeled water molecules as a measure of brain perfusion. This method is less susceptible to baseline drift and intersubject variability, making it a promising technique to measure brain activity in neurodegenerative disorders. ${ }^{144}$ In a cross-sectional study of 34 retired NFL players, all 26 subjects who underwent neuroimaging (10 of whom had some degree of neuropsychiatric deficits) showed decreased blood flow through the left temporal pole and right occipital region compared with healthy controls, as demonstrated by ASL. ${ }^{53}$ In a study of 14 athletes in an adolescent population, ASL showed significantly lower cerebral blood flow in the bilateral frontotemporal regions compared with healthy controls. ${ }^{141}$ These data were consistent with another pediatric series of 12 patients in whom cerebral perfusion was evaluated by a combination of SWI, DTI, proton MR spectroscopy (MRS), and phase contrast angiography. ${ }^{80}$ Methods that correlate functional findings with the presence of subtle neurocognitive deficits in otherwise asymptomatic athletes can suggest the existence of a previously unknown, but suspected, ${ }^{87}$ subtype of CTE. These athletes, who exhibit extremely subtle neurocognitive defects that persist over time, continue to participate in contact sports, potentially placing themselves at higher risk for long-term injury. ${ }^{34,96,134}$

\section{Diffusion Tensor Imaging}

Diffusion tensor imaging is an advanced MRI technique that measures fractional anisotropy (FA), axial diffusivity, and radial diffusivity, which together help to characterize microstructural changes, in particular axonal integrity in vivo. In studies using DTI in boxers who have a history of mTBI, declarative memory and reaction time displayed the greatest negative correlations with FA compared with controls. Sustained boxing activity was correlated with increased apparent diffusion coefficient (a correlative measure of TBI) and/or decreased FA in a variety of structures including the internal capsule, putamen, medial temporal lobe, and inferior frontooccipital fascicles. ${ }^{23,143}$ DTI has also provided evidence that all TBIs, ranging from mild to severe, can result in a degree of axonal damage; the more severe injuries appear to damage both axons and myelin. ${ }^{70}$ In a prospective cohort of 9 high school athletes engaged in hockey and football (1 was diagnosed with concussion within 72 hours of DTI scan, and the other 8 suffered between 26 and 399 subconcussive head blows), DTI detected significantly changed white matter voxels in the athlete with a single concussion. The athletes with multiple subconcussive head blows had significant changes in a percentage of their white matter that was more than 3 times greater than in controls..$^{10}$ In an effort to establish differences between the functionality of fMRI and DTI in the setting of mTBI, 1 study found a lack of consistent findings across both techniques. ${ }^{149}$ This highlights the need for future research to establish a clearer difference in the diagnostic utility of each technique. Moreover, in addition to the architectural and microstructural changes highlighted with the use of DTI, magnetoencephalography has been used to identify changes in functional connectivity; patients with mTBI exhibited weakened local connections and strong long-range connections, displaying an inverse relationship relative to non-mTBI controls. ${ }^{30}$

\section{Magnetic Resonance Spectroscopy}

Magnetic resonance spectroscopy is a method similar to MRI. Although both MRS and MRI exploit the spin- 
relaxation properties of protons, MRI uses this information to create a 2D image of the brain, whereas MRS determines the relative concentrations of various brain metabolites. ${ }^{74}$ In a study of 11 former professional soccer players, MRS revealed a significant increase in choline (a marker for cellular proliferation and tissue damage) and myoinositol (a glial activation marker) compared with age-matched controls. ${ }^{68}$ No neurocognitive deficits were reported in this study group. Another series, which compared 10 concussed athletes with 10 nonconcussed athletes in both acute and chronic injury phases, demonstrated neurochemical impairment in the prefrontal and motor (M1) cortex, particularly a chronic pathological increase in creatine and myoinositol in the M1 cortex..$^{56}$ However, another MRS study of 30 football players, 16 of whom had sustained a concussion in the past 3 years, showed mixed results. No significant group differences were observed for metabolic concentrations; however, correlation analysis revealed a subtle metabolic imbalance between $\gamma$-aminobutyric acid and glutamate concentrations in the primary motor cortex of concussed athletes. ${ }^{138}$ A recent development in MRS introduces a new technique called localized correlation spectroscopy, which allows the measurement and comparison of multiple neurochemicals with one another. In a series of 5 retired professional athletes, all of whom had sustained multiple concussions, this method revealed increased glutamine/glutamate, choline, fucosylated molecules, and phenylalanine levels in the brain. ${ }^{75}$ Given these results, MRS remains a useful adjuvant to conventional scanning techniques.

\section{Positron Emission Tomography}

Positron emission tomography has been indicated for its ability to detect different patterns of 2-(1-\{6-[(2-[fluorine-18]fluoroethyl)(methyl)amino]-2-naphthyl\}-ethylidene)malononitrile ( $\left.{ }^{18} \mathrm{~F}-\mathrm{FDDNP}\right)$ binding, which has been thought to be consistent with tau deposition in autopsies of patients with CTE. ${ }^{87,93,129}$ In a study of 5 retired NFL players with histories of neuropsychiatric deficits, ${ }^{18} \mathrm{~F}-\mathrm{FDDNP}$ PET revealed higher signals in all subcortical regions and the amygdala compared with controls, which suggests tau depositions in these areas. ${ }^{129}$ The study of the 5 players by Small et al. ${ }^{129}$ was followed by a larger study involving ${ }^{18} \mathrm{~F}$ FDDNP PET imaging of 14 retired professional football players (5 of whom were included in the earlier study) with suspected CTE and 24 patients with Alzheimer's dementia. ${ }^{7}$ In vivo imaging suggests that tau deposition in the football player group was consistent with the postmortem pattern of confirmed CTE cases previously described by McKee et al. and Omalu et al. Both methods showed involvement of subcortical structures, the medial temporal lobe, and the frontal cortex. In addition, the FDDNP signal in the suspected CTE group was distinct from that of the AD group, which suggests that this tracer can be specific for CTE. Although FDDNP is also sensitive for other fibrillar insoluble protein aggregates such as TDP-43 and amyloid plaques, this broad specificity can be used as a diagnostic advantage because TDP-43 and $\beta$-amyloid deposition are associated with older cases and more advanced CTE neuropathology (e.g., Stage IV).${ }^{90}$ By quantifying differences in regional loads of multiple protein aggregates in regions of combined neuropathologies, investigators can potentially better define the progression of CTE?

Another set of PET tracers, ${ }^{18} \mathrm{~F}$-florbetapir PET for amyloid plaques and ${ }^{18} \mathrm{~F}-\mathrm{T} 807$ PET for tau, was examined in a retired NFL player with prior multiple concussions..$^{93}$ This patient had a clinical suspicion of CTE given his career history and an insidious onset of memory and cognitive impairments. PET imaging revealed striatal and nigral ${ }^{18} \mathrm{~F}-$ T807 retention consistent with the presence of tauopathy in these areas; however, postmortem evaluation of pathology was not performed, which limited the ability to directly correlate pathological findings with clinical symptoms and PET findings. Furthermore, ${ }^{18} \mathrm{~F}$-florbetapir PET was negative for cerebral amyloidosis, thereby excluding $\mathrm{AD}$, which illustrates that combination scanning can further clarify diagnosis in addition to preventing inappropriate treatment. As of January 2016, there was an active clinical trial investigating the utility of ${ }^{18} \mathrm{~F}-\mathrm{T} 807$ in a larger cohort (clinicaltrials.gov; NCT02266563).

Other PET tracers, such as ${ }^{18} \mathrm{~F}-\mathrm{FDG}$, can also detect metabolic perturbations in the brain. In a series of 19 boxers, ${ }^{18} \mathrm{~F}$-FDG PET showed hypometabolism in the posterior cingulate cortex, parietooccipital region, frontal lobes (Broca's area) bilaterally, and the cerebellum. ${ }^{119}$ These PET studies are significant because for the first time, the pathological component of CTE (tau protein) can be detected premortem. With recent emphasis on early detection of $\mathrm{AD}$, new tau tracers are being developed with enhanced specificity, which will augment their diagnostic ability in the settings of both AD and CTE. ${ }^{150}$ At least 7 PET tracers have been developed, including ${ }^{11} \mathrm{C}-\mathrm{PBB} 3,{ }^{18} \mathrm{~F}-\mathrm{THK}-523$, ${ }^{18} \mathrm{~F}-\mathrm{THK}-5105,{ }^{18} \mathrm{~F}-\mathrm{THK}-5117,{ }^{18} \mathrm{~F}-\mathrm{T} 808,{ }^{18} \mathrm{~F}-\mathrm{FDDNP}$, and ${ }^{18} \mathrm{~F}-\mathrm{T} 807$, although the clinical utility of each has challenges associated with sensitivity and specificity. ${ }^{61}$ However, the wide range of radiological advancements does suggest that micropathological changes in the setting of chronic mTBIs are detectable, and may help formulate a more concrete diagnostic criterion to aid in early detection.

\section{Diagnostic Biomarkers Key Considerations}

Biomarkers are cellular, chemical, or molecular aberrations detectable in a biological fluid that can serve as indicators of the state of biological processes. Although a powerful tool for both diagnosing and understanding neurological disease, an ideal diagnostic biomarker must fulfill 3 key criteria. $19,32,39,57,118$ First, it must be accessible; for a biomarker to be a viable diagnostic option, it must be easily obtained with minimal risk or discomfort to the patient. Following mTBI, CSF may contain elevated proteins from damaged neurons and neuroglia. These proteins can potentially cross the blood-brain barrier (BBB) and enter peripheral circulation, where they can be readily sampled. ${ }^{37}$ Second, a diagnostic biomarker must be detectable; a good biomarker should be easily quantified in assays that are rapid, inexpensive, and robust. Markers that bridge species (i.e., those that are predictive in both humans and in species used in preclinical studies) are superior because they are more amenable to preclinical and clinical trials. Third, a diagnostic biomarker must be predictive; biomarkers should be specific, sensitive, and have 
a high positive predictive value. A high relative expression in a disease state versus a nondisease state is critical, and markers that have a near-zero baseline in a nondisease state are preferred. Moreover, the power of biomarkers lies in early detection; thus, they should be detectable prior to histopathological changes and they should correlate with the severity of damage. ${ }^{11}$

Interest in biomarkers for mTBI has increased dramatically over the past 2 decades following the increased understanding of CTE and the intensifying need for early diagnostics of brain injury. $41,111,112$ However, the development of biomarkers specifically for CTE has proved elusive. Numerous gaps remain in our understanding of the pathophysiological processes leading to the development of CTE. Without this foundation, researchers must sift through a large number of candidate biomarkers. Because a definitive diagnosis can only be made postmortem and the symptoms of CTE overlap considerably with other neurological conditions, it is difficult to directly correlate promising biomarker candidates with CTE. As a result, there is currently a paucity of studies on disease-specific biomarkers of CTE; the focus has been on biomarkers of mTBI instead. Although the connection between mTBI biomarkers and CTE remains to be elucidated, these biomarkers may ultimately prove valuable as clinical screening tools by identifying factors that may predispose individuals to developing CTE. In the future, identifying individuals at risk will be a key component in long-term follow-up studies. A summary of molecular biomarkers that are currently being investigated in the setting of TBIs is given in Table 4.

\section{Blood Biomarkers}

Blood has generated considerable interest as a reservoir for brain injury biomarkers because it can be safely and easily collected. Furthermore, conventional methods such as the enzyme-linked immunosorbent assay have been adapted to detect these various biomarker candidates. However, a number of challenges exist, which may ultimately limit the clinical use of blood-based biomarkers of brain injury. First, the detection of small amounts of biomarkers in blood is often difficult due to their dilution in the large fluid volume that comprises the systemic circulation. ${ }^{71}$ Second, there exists a low signal-to-noise ratio because blood interfaces with most organ systems of the body and contains a complex, native cell population. Third, the BBB also remains a challenge because it prevents diffusion of CNS material into the systemic circulation.

Perhaps the most well-studied biomarker for TBI is S100-B, a regulator of intracellular calcium. Due to its high sensitivity, S100-B has been incorporated into some clinical guidelines. ${ }^{60,139}$ According to the American College of Emergency Physicians/Centers for Disease Control and Prevention, a CT scan is not indicated in the context of acute TBI (less than 4 hours) if serum S100-B levels are less than $0.1 \mu \mathrm{g} / \mathrm{L}$ and there is no evidence of extracranial injury.$^{60}$ However, it should be noted that S100-B is not yet approved by the FDA solely for this purpose and it is currently only used as a supplementary clinical decisionmaking tool. Although levels of S100-B in mild TBI have been shown to be elevated after injury, studies investigat- ing the ability of S100-B to specifically predict the occurrence of postconcussive symptoms and cognitive impairment have proved inconclusive. ${ }^{148}$ The limiting factor for the widespread use of S100-B in the diagnosis of brain injury remains its poor specificity, which is mainly due to extracerebral sources of the protein. In addition to brain, S100-B has been described in Schwann cells, chondrocytes, adipocytes, and exocrine cells. ${ }^{50}$ Furthermore, the mechanism of release of S100-B may not be exclusive to brain injury because elevated levels have also been detected in ischemic reperfusion injury, patients with mood disorders, and cases of polytrauma without head injury. ${ }^{2,115,128}$

Glial fibrillary acidic protein (GFAP), a neurofilament protein, is exclusively expressed by astrocytes. It has been suggested to be a more specific biomarker for brain injury than S100-B. ${ }^{148}$ In patients with polytrauma without brain injury, increased levels were not detected. ${ }^{62}$ A study by Papa et al. reported that GFAP was better able to predict intracranial injury on CT in patients with mild and moderate TBI with a Glasgow Coma Scale score of 14-15. ${ }^{113}$ Using a cutoff of $0.067 \mathrm{ng} / \mathrm{ml}$, GFAP was able to detect the presence of intracranial lesions on CT with a sensitivity of $100 \%$ and a specificity of 55\%. Although S100-B also demonstrated a sensitivity of $100 \%$ using a cutoff of 0.020 $\mathrm{ng} / \mathrm{ml}$, its specificity of $5 \%$ was markedly lower than that of GFAP. Given the promising improvement in specificity of GFAP over S100-B and the utility of S100-B in the clinical guidelines mentioned above, it seems likely that GFAP will eventually replace S100-B as a biomarker for intracranial injury. However, more studies investigating its use and its superior specificity must be performed because the role of GFAP as a biomarker for TBI has not been as extensively studied as that of S100-B.

The glycolytic enzyme, $\gamma$-enolase, otherwise known as neuron-specific enolase (NSE), is another candidate biomarker of TBI. Despite inconclusive studies demonstrating its clinical value in adults, the use of NSE has been proposed as a marker of TBI in the pediatric population and has been shown to have a higher predictive value in this population. ${ }^{71}$ Because NSE is also highly expressed in erythrocytes, care must be taken during sample processing because hemolysis may produce false-positive results. ${ }^{120}$

MicroRNAs (miRNAs) have also emerged as biomarker candidates for TBI in early studies. These short noncoding RNAs have been shown to play important roles in the regulation of messenger RNA expression. Although studies have shown unique miRNA expression profiles in cases of mTBI both in animal models and in humans, there is little overlap due to differing study conditions and the large number of miRNAs. ${ }^{6,114,121}$ A study by Redell et al. reported that levels of miR-16 and miR-92a were decreased in cases of severe TBI but increased in cases of mTBI. ${ }^{121}$ Pasinetti et al. found a unique miRNA signature in veterans who experienced mTBI during their previous deployment, which ranged from 1.2 to 6.6 years before the date of the study. ${ }^{114}$ Further studies are needed to validate these results and to elucidate the miRNAs that can accurately predict $\mathrm{mTBI}$.

\section{Cerebrospinal Fluid Biomarkers}

Cerebrospinal fluid may serve as a promising source of 


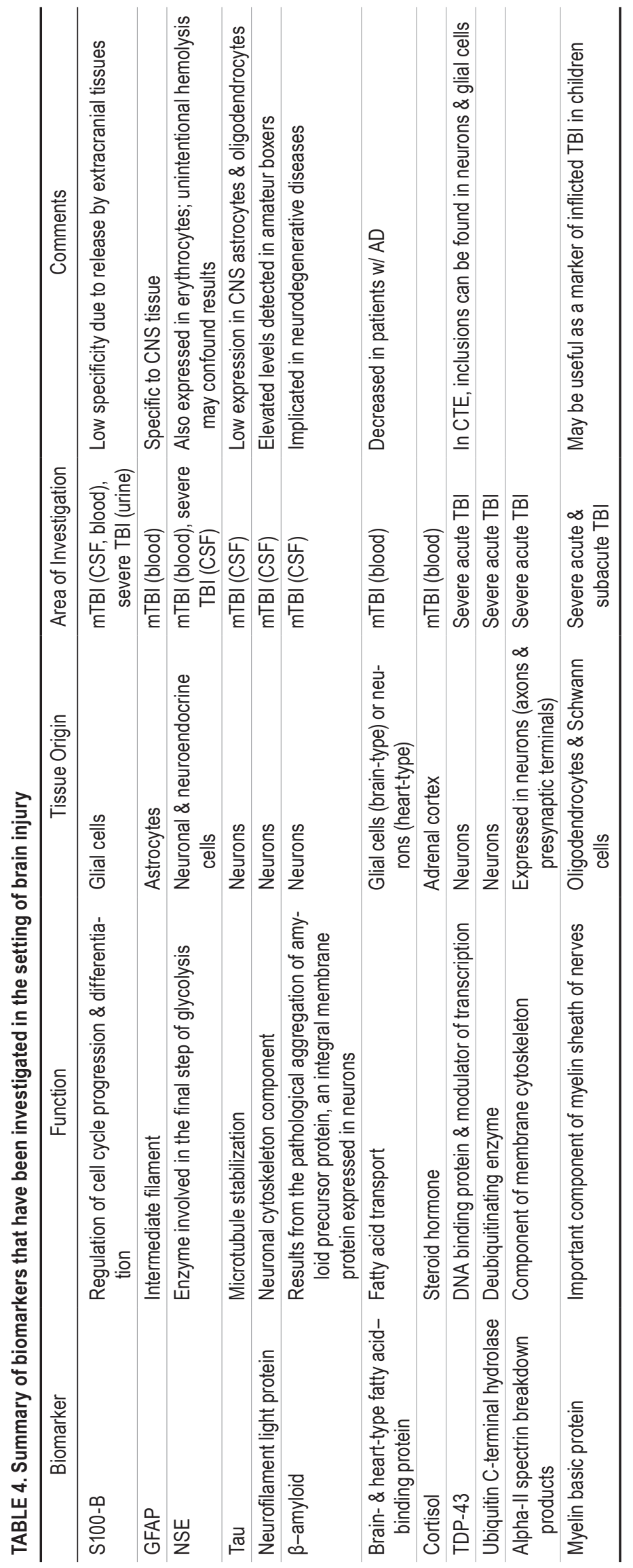


biomarkers for mTBI because it directly interfaces with a large amount of CNS tissue across the blood-CSF barrier. In contrast with blood, CSF does not normally contain significant concentrations of native proteins or cells. ${ }^{125}$ This contributes to higher signal-to-noise ratios to aid in sensitive detection of low concentrations of biomarkers of interest. Early studies have shown that this fluid can be sampled to assess BBB integrity, neuroinflammation, and the presence of CNS malignancy. ${ }^{148}$ Studies have demonstrated that the ratio of CSF to serum albumin can be used as a means to detect disruption of the BBB in severe brain injury; however, these results were not replicated in cases of mTBI. ${ }^{15,29,67,147}$

Tau protein and neurofilaments have emerged as biomarker candidates for axonal injury in CSF because these molecules represent the pathognomonic features found in neurodegenerative diseases, including CTE. Two prospective studies, consisting of 30 and 14 amateur boxers, compared levels of neurofilament light protein and total tau in the CSF to nonboxing healthy controls. ${ }^{101,147}$ The CSF, collected via lumbar puncture within 10 days of a bout and after a rest period, showed increased levels of both proteins compared with samples from controls. Interestingly, in both studies, levels of these proteins correlated with measures of impact number and severity.

Both S100-B and GFAP have received considerable attention as biomarkers of TBI in blood; however, studies in CSF are lacking. The 2 previously mentioned studies that investigated neurofilament light chain and total tau levels in CSF of boxers also included S100-B and GFAP. ${ }^{101,147}$ Although elevated levels were detected, they were not as high as neurofilament light chain and total tau, which suggests that S100-B and GFAP may lack the required sensitivity to detect cases of mTBI in CSF.

Similar to blood biomarkers, NSE is also found in the CSF. NSE has been studied almost exclusively in the setting of severe TBI and has been proposed as a biomarker of brain injury in children. ${ }^{148}$ Studies have shown that CSF NSE levels correlate with clinical outcomes, with higher levels in nonsurvivors after TBI. ${ }^{16,24,126}$ As previously mentioned, the expression of NSE in erythrocytes makes its accurate quantification difficult due to unintentional hemolysis, although this is less of a concern in CSF sampling.

\section{Other Biomarkers}

Many studies on putative biomarkers of mTBI originate in the context of severe injury. To that end, there are a number of promising biomarkers that have yet to be described for cases of mTBI. Urine has recently been explored as a source of biomarkers for severe TBI. In urine samples collected from children and adults with severe TBI, elevated levels of S100-B have been detected and have been found to correlate with serum levels of S100-B. ${ }^{12,51,124}$ Elevated breakdown products of alpha-II spectrin (a structural protein found primarily in neurons) and ubiquitin C-terminal hydrolase (a deubiquitinating enzyme that is also found primarily in neurons) have been described mainly in the context of severe TBI also; these proteins may hold promise for the detection of chronic injury. ${ }^{71,148}$ Because axon injury is a widely described result of TBI, myelin basic protein, which is a component of the myelin sheaths of oligodendrocytes and Schwann cells, has also been investigated. Specifically, it has been proposed as a marker of TBI in children because serum levels have been found to reach a peak concentration 48-72 hours after injury and remain elevated for up to 2 weeks. ${ }^{11}$

Biomarkers specific to the chronic disease processes that result in CTE could prove useful, especially in conjunction with the biomarkers of acute injury. Accumulations of TDP-43 have been described in patients with $\mathrm{CTE}$ as well as in a number of other neurodegenerative conditions. ${ }^{88,103,148}$ A recent review described elevated levels of TDP-43 and its breakdown products in the CSF of 21 patients presenting with severe TBI compared with control CSF samples. ${ }^{148}$ Although assays are available to detect this protein in CSF, studies focusing on patients with chronic injuries are lacking. ${ }^{43}$ There is also evidence supporting the occurrence of chronic pituitary dysfunction as a result of axonal stretching during repetitive head trauma. ${ }^{148}$ It has been estimated that $25 \%-30 \%$ of patients with TBI suffer some degree of posttraumatic hypopituitarism. If correlated to impact exposure history and clinical manifestations of CTE, this finding could serve as a crude estimate of the chronic disease state..$^{1,67,135}$ Other biological biomarkers that have been investigated in a sports context include cortisol as well as brain- and heart-type fatty acidbinding proteins. ${ }^{47,116}$

As a departure from liquid biomarkers, quantitative and qualitative analysis of neuromotor impairments has emerged as a promising tool to predict mTBI progression because eye movement deficiencies are strongly linked to the functional integrity of the injured brain. ${ }^{54}$ Ocular pursuit involves a combination of saccadic eye movement and perceptual stability. The attention required to create such time-based expectancies from sensory information makes ocular tracking an emerging diagnostic tool to assess cognitive impairment. ${ }^{78,79}$ In a study of 17 subjects with chronic postconcussive syndrome, eye tracking via videooculography revealed that gaze error variability was significantly correlated with the FA parameter of the right anterior corona radiata, the left superior cerebellar peduncle, and the corpus callosum as measured by DTI. Gaze error variability in this cohort was also significantly correlated with attention and memory neurocognitive testing. ${ }^{79}$

Modern ocular tracking techniques draw inspiration from methods that have been used in patients with TBI since the time of ancient Egypt. ${ }^{127}$ More recently, however, algorithms for assessing eye tracking have enabled rapid and accurate assessment of the severity of ocular motor disruption associated with structural brain damage. ${ }^{127}$ In cases where MRI and CT scans are inconclusive in the setting of mTBI, ocular evaluations can be a useful adjuvant for diagnosis.

\section{Biomarker Discovery: Current Prospects and Challenges}

Despite the enormous potential of biomarkers to improve treatment and reduce health care costs, their use in the diagnosis of mTBI and CTE remains severely limited. This trend is not specific to sports-related brain injury, but holds for biomarkers in general. For example, more than 
150,000 papers have been published documenting thousands of potential biomarkers, but fewer than 100 of these markers have been validated for clinical use. ${ }^{118} \mathrm{~A}$ recent systematic review examining biomarkers specifically for sports-related brain injury showed that 11 biomarkers have been investigated but none have been clinically validated. ${ }^{111}$ This is partially due to the fact that the use of biomarkers for sports-related injuries and concussion is still a relatively new topic of interest; as a result, more research is needed for biomarker discovery.

Methods for novel biomarker discovery can be classified as unbiased or hypothesis driven. In an unbiased approach, high-throughput screens without preselected antibodies or pathophysiology-based designs are used to identify novel biomarkers. ${ }^{71}$ Numerous methods for unbiased biomarker discovery include phage-linked-enzyme-linked immunosorbent assay, ${ }^{151}$ miRNA modulation, ${ }^{5}$ and high-throughput proteomics techniques combined with bioinformatics. In hypothesis-driven discovery, biomarker candidates are selected based on their abundance in cells known to be affected by TBI. Targets identified are typically validated using multiplex arrays or reverse phase protein microarrays. ${ }^{145,146}$ However, despite the rapidly expanding toolbox for identifying new biomarkers, a massive disconnect still exists between the laboratory and the clinic, partly due to the underreporting of sports-related injuries.

The small pool of potential biomarkers is not the only challenge hindering clinical use. Major pitfalls in the translation of biomarkers of any kind to clinical use stem from the design of clinical trials. ${ }^{35}$ Faults in study design - specifically inadequate patient sample sizes, heterogeneous inclusion criteria, lack of patient information, and insufficient age and sex matching-have been among the foremost difficulties in trials for biomarker validation. Moreover, errors in sample preparation also present challenges. Even with carefully designed trials, many biomarkers fail on the grounds of low sensitivity and specificity. Several strategies exist to augment detection, including: 1) improved assay detection with higher-specificity antibodies, 2) simultaneous detection of multiple biomarkers, or 3) identification of subpopulations for which the given marker is able to provide a sufficient predictive outcome. More importantly, as long as the clinical diagnosis of a concussion and its long-term consequences remain an elusive moving target, it will be difficult to develop a highly sensitive and specific biomarker in blood or CSF, let alone correctly identify patients for screening.

\section{Conclusions}

From the first description of CTE in an American football player ${ }^{108}$ to all of the subsequent research on this matter, both the public and regulatory bodies have realized that sports-related brain injuries is a topic that deserves more attention from clinicians, scientists, and policy makers. The basic science behind mTBI and CTE will continue to be studied, and can offer insights into the mechanisms of other neurodegenerative diseases as well. However, one needs to realize that mTBI and CTE are complex diseases, and no single neuroimaging technique or biomarker can adequately describe the disease. It is critically important for clinicians to understand and be able to interpret and integrate multiple diagnostic tests in the context of each unique patient, all of whom have varying degrees of risk factors. There is also a need to integrate clinical, imaging, and biomarker findings to formulate a more refined definition of mTBI and CTE and how they are distinct from other diseases with similar presentations.

Developments in neuroimaging and diagnostic biomarkers are advancing at a brisk pace. These innovations will continue to be facilitated by programs of various sports organizations (such as the NFL) that aim to place neurosurgeons and neurologists on the sidelines of competitions to make return-to-play decisions. ${ }^{3}$ Only as data collection efforts start to accelerate will we be able to complete the story of the risk factors, epidemiology, pathogenesis, diagnosis, and management of these sports-related brain injuries.

\section{References}

1. Aimaretti G, Ambrosio MR, Di Somma C, Fusco A, Cannavò S, Gasperi M, et al: Traumatic brain injury and subarachnoid haemorrhage are conditions at high risk for hypopituitarism: screening study at 3 months after the brain injury. Clin Endocrinol (Oxf) 61:320-326, 2004

2. Anderson RE, Hansson LO, Nilsson O, Dijlai-Merzoug R, Settergren G: High serum S100B levels for trauma patients without head injuries. Neurosurgery 48:1255-1260, 2001

3. Associated Press: NFL expects to soon have neurological consultants on sidelines. (http://www.nfl.com/news/ story/0ap1000000133506/printable/nfl-expects-to-soonhave-neurological-consultants-on-sidelines) [Accessed February 18, 2016]

4. Astafiev SV, Shulman GL, Metcalf NV, Rengachary J, MacDonald CL, Harrington DL, et al: Abnormal white matter blood-oxygen-level-dependent signals in chronic mild traumatic brain injury. J Neurotrauma 32:1254-1271, 2015

5. Azad TD, Li A, Pendharkar AV, Veeravagu A, Grant GA: Junior Seau: an illustrative case of chronic traumatic encephalopathy and update on chronic sports-related head injury. World Neurosurg 86:515.e11-515.e16, 2016

6. Balakathiresan N, Bhomia M, Chandran R, Chavko M, McCarron RM, Maheshwari RK: MicroRNA let-7i is a promising serum biomarker for blast-induced traumatic brain injury. J Neurotrauma 29:1379-1387, 2012

7. Barrio JR, Small GW, Wong KP, Huang SC, Liu J, Merrill $\mathrm{DA}$, et al: In vivo characterization of chronic traumatic encephalopathy using [F-18]FDDNP PET brain imaging. Proc Natl Acad Sci U S A 112:E2039-E2047, 2015

8. Baugh CM, Kiernan PT, Kroshus E, Daneshvar DH, Montenigro PH, McKee AC, et al: Frequency of headimpact-related outcomes by position in NCAA division I collegiate football players. J Neurotrauma 32:314-326, 2015

9. Baugh CM, Stamm JM, Riley DO, Gavett BE, Shenton ME, Lin A, et al: Chronic traumatic encephalopathy: neurodegeneration following repetitive concussive and subconcussive brain trauma. Brain Imaging Behav 6:244-254, 2012

10. Bazarian JJ, Zhu T, Blyth B, Borrino A, Zhong J: Subjectspecific changes in brain white matter on diffusion tensor imaging after sports-related concussion. Magn Reson Imaging 30:171-180, 2012

11. Berger RP, Adelson PD, Pierce MC, Dulani T, Cassidy LD, Kochanek PM: Serum neuron-specific enolase, S100B, and myelin basic protein concentrations after inflicted and noninflicted traumatic brain injury in children. J Neurosurg 103 (1 Suppl):61-68, 2005 
12. Berger RP, Kochanek PM: Urinary S100B concentrations are increased after brain injury in children: A preliminary study. Pediatr Crit Care Med 7:557-561, 2006

13. Bieniek KF, Ross OA, Cormier KA, Walton RL, SotoOrtolaza A, Johnston AE, et al: Chronic traumatic encephalopathy pathology in a neurodegenerative disorders brain bank. Acta Neuropathol 130:877-889, 2015

14. Blaylock RL, Maroon J: Immunoexcitotoxicity as a central mechanism in chronic traumatic encephalopathy-A unifying hypothesis. Surg Neurol Int 2:107, 2011

15. Blennow K, Jonsson M, Andreasen N, Rosengren L, Wallin A, Hellström PA, et al: No neurochemical evidence of brain injury after blast overpressure by repeated explosions or firing heavy weapons. Acta Neurol Scand 123:245-251, 2011

16. Böhmer AE, Oses JP, Schmidt AP, Perón CS, Krebs CL, Oppitz PP, et al: Neuron-specific enolase, S100B, and glial fibrillary acidic protein levels as outcome predictors in patients with severe traumatic brain injury. Neurosurgery 68: $1624-1631,2011$

17. Borogovac A, Asllani I: Arterial spin labeling (ASL) fMRI: advantages, theoretical constrains, and experimental challenges in neurosciences. Int J Biomed Imaging 2012:818456-13, 2012

18. Brandenburg W, Hallervorden J: [Dementia pugilistica with anatomical findings.] Virchows Arch 325:680-709, 1954 (Ger)

19. Campion S, Aubrecht J, Boekelheide K, Brewster DW, Vaidya VS, Anderson L, et al: The current status of biomarkers for predicting toxicity. Expert Opin Drug Metab Toxicol 9:1391-1408, 2013

20. Casson IR, Viano DC, Haacke EM, Kou Z, LeStrange DG: Is there chronic brain damage in retired NFL players? Neuroradiology, neuropsychology, and neurology examinations of 45 retired players. Sports Health 6:384-395, 2014

21. Centers for Disease Control and Prevention: Nonfatal traumatic brain injuries related to sports and recreation activities among persons aged $\leq 19$ years - United States, 2001-2009. MMWR Morb Mortal Wkly Rep 60:1337-1342, 2011

22. Chamelian L, Reis M, Feinstein A: Six-month recovery from mild to moderate traumatic brain injury: the role of APOE-epsilon4 allele. Brain 127:2621-2628, 2004

23. Chappell MH, Uluğ AM, Zhang L, Heitger MH, Jordan BD, Zimmerman RD, et al: Distribution of microstructural damage in the brains of professional boxers: a diffusion MRI study. J Magn Reson Imaging 24:537-542, 2006

24. Chiaretti A, Barone G, Riccardi R, Antonelli A, Pezzotti $\mathrm{P}$, Genovese O, et al: NGF, DCX, and NSE upregulation correlates with severity and outcome of head trauma in children. Neurology 72:609-616, 2009

25. Corsellis JA, Brierley JB: Observations on the pathology of insidious dementia following head injury. J Ment Sci 105:714-720, 1959

26. Corsellis JA, Bruton CJ, Freeman-Browne D: The aftermath of boxing. Psychol Med 3:270-303, 1973

27. Courville CB: Punch drunk. Its pathogenesis and pathology on the basis of a verified case. Bull Los Angel Neuro Soc 27:160-168, 1962

28. Covassin T, Elbin R, Kontos A, Larson E: Investigating baseline neurocognitive performance between male and female athletes with a history of multiple concussion. J Neurol Neurosurg Psychiatry 81:597-601, 2010

29. Csuka E, Morganti-Kossmann MC, Lenzlinger PM, Joller $\mathrm{H}$, Trentz O, Kossmann T: IL-10 levels in cerebrospinal fluid and serum of patients with severe traumatic brain injury: relationship to IL- 6 , TNF- $\alpha$, TGF- $\beta 1$ and blood-brain barrier function. J Neuroimmunol 101:211-221, 1999

30. da Costa L, Robertson A, Bethune A, MacDonald MJ, Shek PN, Taylor MJ, et al: Delayed and disorganised brain acti- vation detected with magnetoencephalography after mild traumatic brain injury. J Neurol Neurosurg Psychiatry 86:1008-1015, 2015

31. Davis GA, Castellani RJ, McCrory P: Neurodegeneration and sport. Neurosurgery 76:643-656, 2015

32. Di Battista AP, Rhind SG, Baker AJ: Application of bloodbased biomarkers in human mild traumatic brain injury. Front Neurol 4:44, 2013

33. Ding K, Marquez de la Plata C, Wang JY, Mumphrey M, Moore C, Harper C, et al: Cerebral atrophy after traumatic white matter injury: correlation with acute neuroimaging and outcome. J Neurotrauma 25:1433-1440, 2008

34. Donovan V, Kim C, Anugerah AK, Coats JS, Oyoyo U, Pardo AC, et al: Repeated mild traumatic brain injury results in long-term white-matter disruption. J Cereb Blood Flow Metab 34:715-723, 2014

35. Drucker E, Krapfenbauer K: Pitfalls and limitations in translation from biomarker discovery to clinical utility in predictive and personalised medicine. EPMA J 4:7, 2013

36. Eierud C, Craddock RC, Fletcher S, Aulakh M, King-Casas B, Kuehl D, et al: Neuroimaging after mild traumatic brain injury: review and meta-analysis. Neuroimage Clin 4:283294,2014

37. Finnoff JT, Jelsing EJ, Smith J: Biomarkers, genetics, and risk factors for concussion. PM R 3 (10 Suppl 2):S452S459, 2011

38. Gale SD, Baxter L, Roundy N, Johnson SC: Traumatic brain injury and grey matter concentration: a preliminary voxel based morphometry study. J Neurol Neurosurg Psychiatry 76:984-988, 2005

39. Gandy S, Ikonomovic MD, Mitsis E, Elder G, Ahlers ST, Barth J, et al: Chronic traumatic encephalopathy: clinicalbiomarker correlations and current concepts in pathogenesis. Mol Neurodegener 9:37, 2014

40. Gasparotti R, Pinelli L, Liserre R: New MR sequences in daily practice: susceptibility weighted imaging. A pictorial essay. Insights Imaging 2:335-347, 2011

41. Gavett BE, Cantu RC, Shenton M, Lin AP, Nowinski CJ, McKee AC, et al: Clinical appraisal of chronic traumatic encephalopathy: current perspectives and future directions. Curr Opin Neurol 24:525-531, 2011

42. Gavett BE, Stern RA, McKee AC: Chronic traumatic encephalopathy: a potential late effect of sport-related concussive and subconcussive head trauma. Clin Sports Med 30:179-188, xi, 2011

43. Geser F, Prvulovic D, O’Dwyer L, Hardiman O, Bede P, Bokde ALW, et al: On the development of markers for pathological TDP-43 in amyotrophic lateral sclerosis with and without dementia. Prog Neurobiol 95:649-662, 2011

44. Giza CC, Hovda DA: The new neurometabolic cascade of concussion. Neurosurgery 75 (Suppl 4):S24-S33, 2014

45. Giza CC, Kutcher JS, Ashwal S, Barth J, Getchius TSD, Gioia GA, et al: Summary of evidence-based guideline update: evaluation and management of concussion in sports: report of the Guideline Development Subcommittee of the American Academy of Neurology. Neurology 80:22502257, 2013

46. Goldstein LE, Fisher AM, Tagge CA, Zhang XL, Velisek L, Sullivan JA, et al: Chronic traumatic encephalopathy in blast-exposed military veterans and a blast neurotrauma mouse model. Sci Transl Med 4:134ra60, 2012

47. Graham MR, Myers T, Evans P, Davies B, Cooper SM, Bhattacharya $\mathrm{K}$, et al: Direct hits to the head during amateur boxing is associated with a rise in serum biomarkers for brain injury. Int J Immunopathol Pharmacol 24:119-125, 2011

48. Gronwall D, Wrightson P: Cumulative effect of concussion. Lancet 2:995-997, 1975

49. Hagmann P, Jonasson L, Maeder P, Thiran JP, Wedeen VJ, 
Meuli R: Understanding diffusion MR imaging techniques: from scalar diffusion-weighted imaging to diffusion tensor imaging and beyond. Radiographics 26 (Suppl 1):S205S223, 2006

50. Haimoto H, Hosoda S, Kato K: Differential distribution of immunoreactive S100-alpha and S100-beta proteins in normal nonnervous human tissues. Lab Invest 57:489-498, 1987

51. Hallén M, Karlsson M, Carlhed R, Hallgren T, Bergenheim M: S-100B in serum and urine after traumatic head injury in children. J Trauma 69:284-289, 2010

52. Han SD, Drake AI, Cessante LM, Jak AJ, Houston WS, Delis DC, et al: Apolipoprotein E and traumatic brain injury in a military population: evidence of a neuropsychological compensatory mechanism? J Neurol Neurosurg Psychiatry 78: 1103-1108, 2007

53. Hart J Jr, Kraut MA, Womack KB, Strain J, Didehbani N, Bartz E, et al: Neuroimaging of cognitive dysfunction and depression in aging retired National Football League players: a cross-sectional study. JAMA Neurol 70:326-335, 2013

54. Heitger MH, Jones RD, Macleod AD, Snell DL, Frampton $\mathrm{CM}$, Anderson TJ: Impaired eye movements in post-concussion syndrome indicate suboptimal brain function beyond the influence of depression, malingering or intellectual ability. Brain 132:2850-2870, 2009

55. Helmer KG, Pasternak O, Fredman E, Preciado RI, Koerte IK, Sasaki T, et al: Hockey concussion education project, part 1. Susceptibility-weighted imaging study in male and female ice hockey players over a single season. $\mathbf{J}$ Neurosurg 120:864-872, 2014

56. Henry LC, Tremblay S, Leclerc S, Khiat A, Boulanger $\mathrm{Y}$, Ellemberg D, et al: Metabolic changes in concussed American football players during the acute and chronic post-injury phases. BMC Neurol 11:105, 2011

57. Hergenroeder GW, Redell JB, Moore AN, Dash PK: Biomarkers in the clinical diagnosis and management of traumatic brain injury. Mol Diagn Ther 12:345-358, 2008

58. Hoshino S, Tamaoka A, Takahashi M, Kobayashi S, Furukawa T, Oaki Y, et al: Emergence of immunoreactivities for phosphorylated tau and amyloid-beta protein in chronic stage of fluid percussion injury in rat brain. Neuroreport 9:1879-1883, 1998

59. Hughes DG, Jackson A, Mason DL, Berry E, Hollis S, Yates DW: Abnormalities on magnetic resonance imaging seen acutely following mild traumatic brain injury: correlation with neuropsychological tests and delayed recovery. Neuroradiology 46:550-558, 2004

60. Jagoda AS, Bazarian JJ, Bruns JJ Jr, Cantrill SV, Gean AD, Howard PK, et al: Clinical policy: neuroimaging and decisionmaking in adult mild traumatic brain injury in the acute setting. J Emerg Nurs 35:e5-e40, 2009

61. James OG, Doraiswamy PM, Borges-Neto S: PET imaging of tau pathology in Alzheimer's disease and tauopathies. Front Neurol 6:38, 2015

62. Jeter CB, Hergenroeder GW, Hylin MJ, Redell JB, Moore AN, Dash PK: Biomarkers for the diagnosis and prognosis of mild traumatic brain injury/concussion. J Neurotrauma 30:657-670, 2013

63. Johnson B, Zhang K, Gay M, Horovitz S, Hallett M, Sebastianelli W, et al: Alteration of brain default network in subacute phase of injury in concussed individuals: restingstate fMRI study. Neuroimage 59:511-518, 2012

64. Johnson VE, Stewart W, Smith DH: Widespread $\tau$ and amyloid- $\beta$ pathology many years after a single traumatic brain injury in humans. Brain Pathol 22:142-149, 2012

65. Johnston KM, Ptito A, Chankowsky J, Chen JK: New frontiers in diagnostic imaging in concussive head injury. Clin J Sport Med 11:166-175, 2001
66. Jordan BD: The clinical spectrum of sport-related traumatic brain injury. Nat Rev Neurol 9:222-230, 2013

67. Kelly DF, Gonzalo IT, Cohan P, Berman N, Swerdloff R, Wang C: Hypopituitarism following traumatic brain injury and aneurysmal subarachnoid hemorrhage: a preliminary report. J Neurosurg 93:743-752, 2000

68. Koerte IK, Lin AP, Muehlmann M, Merugumala S, Liao $\mathrm{H}$, Starr T, et al: Altered neurochemistry in former professional soccer players without a history of concussion. J Neurotrauma 32:1287-1293, 2015

69. Kossmann T, Hans VH, Imhof HG, Stocker R, Grob P, Trentz O, et al: Intrathecal and serum interleukin- 6 and the acute-phase response in patients with severe traumatic brain injuries. Shock 4:311-317, 1995

70. Kraus MF, Susmaras T, Caughlin BP, Walker CJ, Sweeney JA, Little DM: White matter integrity and cognition in chronic traumatic brain injury: a diffusion tensor imaging study. Brain 130:2508-2519, 2007

71. Kulbe JR, Geddes JW: Current status of fluid biomarkers in mild traumatic brain injury. Exp Neurol 275:334-352, 2016

72. Kutner KC, Erlanger DM, Tsai J, Jordan B, Relkin NR: Lower cognitive performance of older football players possessing apolipoprotein E epsilon4. Neurosurgery 47:651658,2000

73. Levine B, Kovacevic N, Nica EI, Cheung G, Gao F, Schwartz ML, et al: The Toronto traumatic brain injury study: injury severity and quantified MRI. Neurology 70:771-778, 2008

74. Lin AP, Liao HJ, Merugumala SK, Prabhu SP, Meehan WP III, Ross BD: Metabolic imaging of mild traumatic brain injury. Brain Imaging Behav 6:208-223, 2012

75. Lin AP, Ramadan S, Stern RA, Box HC, Nowinski CJ, Ross $\mathrm{BD}$, et al: Changes in the neurochemistry of athletes with repetitive brain trauma: preliminary results using localized correlated spectroscopy. Alzheimers Res Ther 7:13, 2015

76. List J, Ott S, Bukowski M, Lindenberg R, Flöel A: Cognitive function and brain structure after recurrent mild traumatic brain injuries in young-to-middle-aged adults. Front Hum Neurosci 9:228, 2015

77. MacKenzie JD, Siddiqi F, Babb JS, Bagley LJ, Mannon LJ, Sinson GP, et al: Brain atrophy in mild or moderate traumatic brain injury: a longitudinal quantitative analysis. AJNR Am J Neuroradiol 23:1509-1515, 2002

78. Maruta J, Ghajar J: Detecting eye movement abnormalities from concussion. Prog Neurol Surg 28:226-233, 2014

79. Maruta J, Suh M, Niogi SN, Mukherjee P, Ghajar J: Visual tracking synchronization as a metric for concussion screening. J Head Trauma Rehabil 25:293-305, 2010

80. Maugans TA, Farley C, Altaye M, Leach J, Cecil KM: Pediatric sports-related concussion produces cerebral blood flow alterations. Pediatrics 129:28-37, 2012

81. Mawdsley C, Ferguson FR: Neurological disease in boxers. Lancet 2:795-801, 1963

82. Mayer AR, Mannell MV, Ling J, Gasparovic C, Yeo RA: Functional connectivity in mild traumatic brain injury. Hum Brain Mapp 32:1825-1835, 2011

83. McAllister TW, Flashman LA, Maerlender A, Greenwald RM, Beckwith JG, Tosteson TD, et al: Cognitive effects of one season of head impacts in a cohort of collegiate contact sport athletes. Neurology 78: 1777-1784, 2012

84. McCrea M, Kelly JP, Kluge J, Ackley B, Randolph C: Standardized assessment of concussion in football players. Neurology 48:586-588, 1997

85. McCrea M, Kelly JP, Randolph C, Kluge J, Bartolic E, Finn $\mathrm{G}$, et al: Standardized assessment of concussion (SAC): onsite mental status evaluation of the athlete. J Head Trauma Rehabil 13:27-35, 1998

86. McKee AC, Cairns NJ, Dickson DW, Folkerth RD, Dirk Keene C, Litvan I, et al: The first NINDS/NIBIB con- 
sensus meeting to define neuropathological criteria for the diagnosis of chronic traumatic encephalopathy. Acta Neuropathol:1-12, 2015

87. McKee AC, Cantu RC, Nowinski CJ, Hedley-Whyte ET, Gavett BE, Budson AE, et al: Chronic traumatic encephalopathy in athletes: progressive tauopathy after repetitive head injury. J Neuropathol Exp Neurol 68:709-735, 2009

88. McKee AC, Gavett BE, Stern RA, Nowinski CJ, Cantu $\mathrm{RC}$, Kowall NW, et al: TDP-43 proteinopathy and motor neuron disease in chronic traumatic encephalopathy. $\mathbf{J}$ Neuropathol Exp Neurol 69:918-929, 2010

89. McKee AC, Stein TD, Kiernan PT, Alvarez VE: The neuropathology of chronic traumatic encephalopathy. Brain Pathol 25:350-364, 2015

90. McKee AC, Stern RA, Nowinski CJ, Stein TD, Alvarez VE, Daneshvar DH, et al: The spectrum of disease in chronic traumatic encephalopathy. Brain 136:43-64, 2013

91. Meehan W III, Mannix R, Zafonte R, Pascual-Leone A: Chronic traumatic encephalopathy and athletes. Neurology 85:1504-1511, 2015

92. Min SW, Chen X, Tracy TE, Li Y, Zhou Y, Wang C, et al: Critical role of acetylation in tau-mediated neurodegeneration and cognitive deficits. Nat Med 21:1154-1162, 2015

93. Mitsis EM, Riggio S, Kostakoglu L, Dickstein DL, Machac J, Delman B, et al: Tauopathy PET and amyloid PET in the diagnosis of chronic traumatic encephalopathies: studies of a retired NFL player and of a man with FTD and a severe head injury. Transl Psychiatry 4:e441, 2014

94. Montenigro PH, Baugh CM, Daneshvar DH, Mez J, Budson $\mathrm{AE}, \mathrm{Au} \mathrm{R}$, et al: Clinical subtypes of chronic traumatic encephalopathy: literature review and proposed research diagnostic criteria for traumatic encephalopathy syndrome. Alzheimers Res Ther 6:68, 2014

95. Moseley ME, Liu C, Rodriguez S, Brosnan T: Advances in magnetic resonance neuroimaging. Neurol Clin 27:1-19, xiii, 2009

96. Mouzon BC, Bachmeier C, Ferro A, Ojo JO, Crynen G, Acker CM, et al: Chronic neuropathological and neurobehavioral changes in a repetitive mild traumatic brain injury model. Ann Neurol 75:241-254, 2014

97. Nakamura K, Greenwood A, Binder L, Bigio EH, Denial S, Nicholson L, et al: Proline isomer-specific antibodies reveal the early pathogenic tau conformation in Alzheimer's disease. Cell 149:232-244, 2012

98. Nakamura K, Zhen Zhou X, Ping Lu K: Cis phosphorylated tau as the earliest detectable pathogenic conformation in Alzheimer disease, offering novel diagnostic and therapeutic strategies. Prion 7:117-120, 2013

99. Nakamura K, Zhou XZ, Lu KP: Distinct functions of cis and trans phosphorylated tau in Alzheimer's disease and their therapeutic implications. Curr Mol Med 13:1098-1109, 2013

100. National Institute of Neurological Disorders and Stroke: Report from the First NIH Consensus Conference to Define the Neuropathological Criteria for the Diagnosis of Chronic Traumatic Encephalopathy. (http://www. ninds.nih.gov/research/tbi/ReportFirstNIHConsensus Conference.htm) [Accessed February 18, 2016]

101. Neselius S, Brisby H, Theodorsson A, Blennow K, Zetterberg H, Marcusson J: CSF-biomarkers in Olympic boxing: diagnosis and effects of repetitive head trauma. PLoS One 7:e33606, 2012

102. Neubuerger KT, Sinton DW, Denst J: Cerebral atrophy associated with boxing. AMA Arch Neurol Psychiatry 81:403408, 1959

103. Neumann M, Sampathu DM, Kwong LK, Truax AC, Micsenyi MC, Chou TT, et al: Ubiquitinated TDP-43 in frontotemporal lobar degeneration and amyotrophic lateral sclerosis. Science 314:130-133, 2006
104. Nguyen ML, Willows B, Khan R, Chi A, Kim L, Nour SG, et al: The potential role of magnetic resonance spectroscopy in image-guided radiotherapy. Front Oncol 4:91, 2014

105. Niogi SN, Mukherjee P: Diffusion tensor imaging of mild traumatic brain injury. J Head Trauma Rehabil 25:241255,2010

106. Ojo JO, Mouzon B, Greenberg MB, Bachmeier C, Mullan M, Crawford F: Repetitive mild traumatic brain injury augments tau pathology and glial activation in aged hTau mice. J Neuropathol Exp Neurol 72:137-151, 2013

107. Omalu B, Bailes J, Hamilton RL, Kamboh MI, Hammers J, Case M, et al: Emerging histomorphologic phenotypes of chronic traumatic encephalopathy in American athletes. Neurosurgery 69:173-183, 2011

108. Omalu BI, Dekosky ST, Minster RL, Kamboh MI, Hamilton RL, Wecht CH: Chronic traumatic encephalopathy in a National Football League player. Neurosurgery 57:128-134, 2005

109. Omalu BI, Fitzsimmons RP, Hammers J, Bailes J: Chronic traumatic encephalopathy in a professional American wrestler. J Forensic Nurs 6: 130-136, 2010

110. Omalu BI, Hamilton RL, Kamboh MI, DeKosky ST, Bailes J: Chronic traumatic encephalopathy (CTE) in a National Football League Player: Case report and emerging medicolegal practice questions. J Forensic Nurs 6:40-46, 2010

111. Papa L, Ramia MM, Edwards D, Johnson BD, Slobounov SM: Systematic review of clinical studies examining biomarkers of brain injury in athletes after sports-related concussion. J Neurotrauma 32:661-673, 2015

112. Papa L, Ramia MM, Kelly JM, Burks SS, Pawlowicz A, Berger RP: Systematic review of clinical research on biomarkers for pediatric traumatic brain injury. $\mathbf{J}$ Neurotrauma 30:324-338, 2013

113. Papa L, Silvestri S, Brophy GM, Giordano P, Falk JL, Braga CF, et al: GFAP out-performs S100 $\beta$ in detecting traumatic intracranial lesions on computed tomography in trauma patients with mild traumatic brain injury and those with extracranial lesions. J Neurotrauma 31:1815-1822, 2014

114. Pasinetti GM, Ho L, Dooley C, Abbi B, Lange G: Select non-coding RNA in blood components provide novel clinically accessible biological surrogates for improved identification of traumatic brain injury in OEF/OIF Veterans. Am J Neurodegener Dis 1:88-98, 2012

115. Pelinka LE, Harada N, Szalay L, Jafarmadar M, Redl H, Bahrami S: Release of S100B differs during ischemia and reperfusion of the liver, the gut, and the kidney in rats. Shock 21:72-76, 2004

116. Pelsers MMAL, Hanhoff T, Van der Voort D, Arts B, Peters $\mathrm{M}$, Ponds R, et al: Brain- and heart-type fatty acid-binding proteins in the brain: tissue distribution and clinical utility. Clin Chem 50:1568-1575, 2004

117. Petcharunpaisan S, Ramalho J, Castillo M: Arterial spin labeling in neuroimaging. World J Radiol 2:384-398, 2010

118. Poste G: Bring on the biomarkers. Nature 469:156-157, 2011

119. Provenzano FA, Jordan B, Tikofsky RS, Saxena C, Van Heertum RL, Ichise M: F-18 FDG PET imaging of chronic traumatic brain injury in boxers: a statistical parametric analysis. Nucl Med Commun 31:952-957, 2010

120. Ramont L, Thoannes H, Volondat A, Chastang F, Millet MC, Maquart FX: Effects of hemolysis and storage condition on neuron-specific enolase (NSE) in cerebrospinal fluid and serum: implications in clinical practice. Clin Chem Lab Med 43:1215-1217, 2005

121. Redell JB, Moore AN, Ward NH III, Hergenroeder GW, Dash PK: Human traumatic brain injury alters plasma microRNA levels. J Neurotrauma 27:2147-2156, 2010

122. Roberts AH: Brain Damage in Boxers: A Study of the 
Prevalence of Traumatic Encephalopathy Among Ex-Professional Boxers. London: Pitman Medical \& Scientific Publishing, 1969

123. Roberts GW, Whitwell HL, Acland PR, Bruton CJ: Dementia in a punch-drunk wife. Lancet 335:918-919, 1990

124. Rodríguez-Rodríguez A, Egea-Guerrero JJ, León-Justel A, Gordillo-Escobar E, Revuelto-Rey J, Vilches-Arenas A, et al: Role of S100B protein in urine and serum as an early predictor of mortality after severe traumatic brain injury in adults. Clin Chim Acta 414:228-233, 2012

125. Romeo MJ, Espina V, Lowenthal M, Espina BH, Petricoin EF III, Liotta LA: CSF proteome: a protein repository for potential biomarker identification. Expert Rev Proteomics 2:57-70, 2005

126. Ross SA, Cunningham RT, Johnston CF, Rowlands BJ: Neuron-specific enolase as an aid to outcome prediction in head injury. Br J Neurosurg 10:471-476, 1996

127. Samadani U, Ritlop R, Reyes M, Nehrbass E, Li M, Lamm $\mathrm{E}$, et al: Eye tracking detects disconjugate eye movements associated with structural traumatic brain injury and concussion. J Neurotrauma 32:548-556, 2015

128. Schroeter ML, Sacher J, Steiner J, Schoenknecht P, Mueller K: Serum S100B represents a new biomarker for mood disorders. Curr Drug Targets 14:1237-1248, 2013

129. Small GW, Kepe V, Siddarth P, Ercoli LM, Merrill DA, Donoghue N, et al: PET scanning of brain tau in retired national football league players: preliminary findings. Am J Geriatr Psychiatry 21:138-144, 2013

130. Smith DH, Johnson VE, Stewart W: Chronic neuropathologies of single and repetitive TBI: substrates of dementia? Nat Rev Neurol 9:211-221, 2013

131. Solomon GS, Zuckerman SL: Chronic traumatic encephalopathy in professional sports: retrospective and prospective views. Brain Inj 29:164-170, 2015

132. Stern RA, Riley DO, Daneshvar DH, Nowinski CJ, Cantu $\mathrm{RC}, \mathrm{McKee} \mathrm{AC}$ : Long-term consequences of repetitive brain trauma: chronic traumatic encephalopathy. PM R 3 (10 Suppl 2):S460-S467, 2011

133. Strain JF, Womack KB, Didehbani N, Spence JS, Conover $\mathrm{H}$, Hart J Jr, et al: Imaging correlates of memory and concussion history in retired National Football League Athletes. JAMA Neurol 72:773-780, 2015

134. Talavage TM, Nauman EA, Breedlove EL, Yoruk U, Dye AE, Morigaki KE, et al: Functionally-detected cognitive impairment in high school football players without clinically-diagnosed concussion. J Neurotrauma 31:327-338, 2014

135. Tanriverdi F, Senyurek H, Unluhizarci K, Selcuklu A, Casanueva FF, Kelestimur F: High risk of hypopituitarism after traumatic brain injury: a prospective investigation of anterior pituitary function in the acute phase and 12 months after trauma. J Clin Endocrinol Metab 91:2105-2111, 2006

136. Tong KA, Ashwal S, Holshouser BA, Nickerson JP, Wall CJ, Shutter LA, et al: Diffuse axonal injury in children: clinical correlation with hemorrhagic lesions. Ann Neurol 56:36-50, 2004

137. Toth A, Kovacs N, Perlaki G, Orsi G, Aradi M, Komaromy $\mathrm{H}$, et al: Multi-modal magnetic resonance imaging in the acute and sub-acute phase of mild traumatic brain injury: can we see the difference? J Neurotrauma 30:2-10, 2013

138. Tremblay S, Beaulé V, Proulx S, Tremblay S, Marjańska M, Doyon J, et al: Multimodal assessment of primary motor cortex integrity following sport concussion in asymptomatic athletes. Clin Neurophysiol 125: 1371-1379, 2014

139. Undén J, Ingebrigtsen T, Romner B: Scandinavian guide- lines for initial management of minimal, mild and moderate head injuries in adults: an evidence and consensus-based update. BMC Med 11:50, 2013

140. Victoroff J: Traumatic encephalopathy: review and provisional research diagnostic criteria. NeuroRehabilitation 32:211-224, 2013

141. Wang Y, West JD, Bailey JN, Westfall DR, Xiao H, Arnold TW, et al: Decreased cerebral blood flow in chronic pediatric mild TBI: an MRI perfusion study. Dev Neuropsychol 40:40-44, 2015

142. Warner MA, Youn TS, Davis T, Chandra A, Marquez de la Plata C, Moore C, et al: Regionally selective atrophy after traumatic axonal injury. Arch Neurol 67:1336-1344, 2010

143. Wilde EA, Hunter J, Li X, Amador C, Hanten G, Newsome $\mathrm{M}$, et al: Chronic effects of boxing: DTI and cognitive findings. J Neurotrauma [epub ahead of print], 2015

144. Wolk DA, Detre JA: Arterial spin labeling MRI: an emerging biomarker for Alzheimer's disease and other neurodegenerative conditions. Curr Opin Neurol 25:421-428, 2012

145. Yang SH, Gangidine M, Pritts TA, Goodman MD, Lentsch AB: Interleukin 6 mediates neuroinflammation and motor coordination deficits after mild traumatic brain injury and brief hypoxia in mice. Shock 40:471-475, 2013

146. Yang SH, Gustafson J, Gangidine M, Stepien D, Schuster $\mathrm{R}$, Pritts TA, et al: A murine model of mild traumatic brain injury exhibiting cognitive and motor deficits. J Surg Res 184:981-988, 2013

147. Zetterberg H, Hietala MA, Jonsson M, Andreasen N, Styrud E, Karlsson I, et al: Neurochemical aftermath of amateur boxing. Arch Neurol 63:1277-1280, 2006

148. Zetterberg H, Smith DH, Blennow K: Biomarkers of mild traumatic brain injury in cerebrospinal fluid and blood. Nat Rev Neurol 9:201-210, 2013

149. Zhang K, Johnson B, Pennell D, Ray W, Sebastianelli W, Slobounov S: Are functional deficits in concussed individuals consistent with white matter structural alterations: combined FMRI \& DTI study. Exp Brain Res 204:57-70, 2010

150. Zhang W, Arteaga J, Cashion DK, Chen G, Gangadharmath U, Gomez LF, et al: A highly selective and specific PET tracer for imaging of tau pathologies. J Alzheimers Dis 31:601-612, 2012

151. Zhang Z, Xu L, Wang Z: Screening serum biomarkers for early primary hepatocellular carcinoma using a phage display technique. J Clin Lab Anal 25:402-408, 2011

152. Zhou Y, Kierans A, Kenul D, Ge Y, Rath J, Reaume J, et al: Mild traumatic brain injury: longitudinal regional brain volume changes. Radiology 267:880-890, 2013

\section{Disclosures}

The authors report no conflict of interest concerning the materials or methods used in this study or the findings specified in this paper.

\section{Author Contributions}

Conception and design: Grant, Pan, Ho. Drafting the article: Pan, Connolly, Dangelmajer, Kintzing. Critically revising the article: Grant, Pan, Connolly, Dangelmajer, Kintzing. Reviewed submitted version of manuscript: Grant, Pan, Connolly, Dangelmajer, Kintzing.

\section{Correspondence}

Gerald Grant, Department of Neurosurgery, Stanford University Medical Center, 300 Pasteur Dr., Stanford, CA 94305-5327. email: gerald.grant@stanford.edu. 